\title{
Effect of corporal punishment on Sudanese pupils from parent's perspectives - part 2
}

\begin{abstract}
Despite the fact that corporal punishment (cp) in schools and homes proved to be of serious consequences and of no benefit, it is still an acceptable tool of disciplining children over the world notably Sudan against national acts and international convention. The importance of this research is to serve the field of child protection with background information needed for strategic planning for the prevention and promotion of positive discipline. The aim was to Study the impact of corporal punishment on pupil's academic performance and behaviors form parent's perspective. Through comparative analytical study included 200 parents from two schools. Where School (A) using corporal punishment and school (B) declaring not using corporal punishment. The study was conducted in the period from first of June to 30th of July 2013 using structured questionnaires that assessing socio demographic data, use of corporal punishment, believes behavior and academic consequences. Variables were completed and analyzed using parametric and non-parametric test within SPSS 16. The majority of parents were using $\mathrm{cp}$ to discipline their children at homes $(83.4 \%)$. Parental believes about $\mathrm{cp}$ as right and effective tool of child discipline; increase home/school CP and decrease child number of friends. Mother Low education was significantly associated with the use of CP ( $p$ value 0.02 ). Most of the parents found $\mathrm{CP}$ of no benefits in the long run. The use of $\mathrm{CP}$ at home acts as moderator with school CP that made the child dislike school and significantly increases children absence from school. Low parent's education, low income, parent's beliefs about CP and the presence of domestic violence were proved as predictors of use of $\mathrm{CP}$ at homes. Negative child characteristics and recurrent school requisition for Parents were significantly related to school (A), both p values (0.01). Positive child characteristics significantly related to school (B). Although parents claimed that they rarely used CP in disciplining their children this rare use proved of negative consequences and of no benefits in long term and moral internalization. Reducing use of corporal punishment is found to be significantly associated to good behaviors and academic success. The research was replicating other international studies except increase rates of $\mathrm{CP}$ in children from 6-14years, the use of $\mathrm{CP}$ by the parent regardless of their age group. Using $\mathrm{cp}$ in School or at home decrease sense of safety and put the child at risk of bullying or violence.
\end{abstract}

Volume 4 Issue 2 - 2016

\author{
Nahid M Elhassan \\ Hamad Medical Corporation-Psychiatry Department, University \\ of Medical Science and Technology, Sudan
}

\begin{abstract}
Correspondence: Nahid Mohammed Elhassan Ali, Assistant professor, University of Medical Science and Technology, Hamad Medical Corporation-Psychiatry Department, P.O Box 3050, Sudan,Tel+97430384007, Email nhfadul@gmail.com
\end{abstract}

Received: November 09, 2015 | Published: February 05, 2016

\section{Case presentation}

\section{Domestic violence}

$(28 \%)$ of the children were watching their parents during quarrels. That included physical violence $(68.7 \%)$. The majority of parents were using $\mathrm{CP}$ to discipline their children at homes (83.4\%). While $92.7 \%$ were rarely using $\mathrm{CP}$, only $7.2 \%$ of them were frequently using CP. Most of the parents claimed that CP changed their children's behavior temporarily (49.7\%). $39.2 \%$ of them claimed that $\mathrm{CP}$ changed their children's behavior permanently. Only $11.2 \%$ of parents thought that CP failed to change their children's behavior. Almost two thirds of parents $(66.7 \%)$ found that $\mathrm{CP}$ was helpful in immediate child compliance with orders. Almost all parents were using reward in reinforcing child's positive behavior (99.5\%). Among them $42.9 \%$ were using reward usually, 37.6 were using it always and only $19.6 \%$ were using reward rarely.

\section{The relationship between school and home}

Almost all the parents (94.0\%) thought that their children like their schools and $(11.0 \%)$ of them thought that they like it to some extent. No significant difference was found between the two schools as indicated by $p$ value (0.5). Almost all the parents were communicating with their children's schools (99.5\%). There was significant difference between the two schools regarding this variable as indicated by $\mathrm{p}$ value (0.001). Where the communication in school (A)-using corporal punishment- was $100 \%$ and school (B)-not using corporal punishment- was $89.0 \%$. Almost all the parents claimed that the school impact on their children's academic performance and behavior was positive $(97.5 \%),(94.0 \%)$ respectively. No significant difference was found between school (A) and (B).

$(47.0 \%)$ of parents claimed that their children's school was using CP and (44\%) of parent claimed that their children's school wasn't using CP. No significant difference between school (A) and (B) was found as indicated by $\mathrm{p}$ value $(0.53)$. The majorities of parents $(73.7 \%)$ accept the use of CP with their children at schools. Although (53.9\%) of them, accept it with some reservations. Almost all the parents were against ending $\mathrm{CP}$ in schools $(94.8 \%)$. There was significant difference between school (A) and (B) as indicated by $\mathrm{p}$ value (0.04). Where $(97.9 \%)$ of parents with school (B)-school not using cp- were against ending $\mathrm{cp}$ ! (Figure 1).

Parents from school (A) were significantly more requested to come to school $\mathrm{p}$ value $(0.01)$. While reasons of school requisition 
in school (B) were mainly due to academic problems (87.5\%). The other reasons of requisitions were confined only to school (A) and represented (12.5\%). These reasons were as follows; bullying $(4.2 \%)$, confrontations with teachers $(4.2 \%)$ and vandalism $(4.1 \%)$.

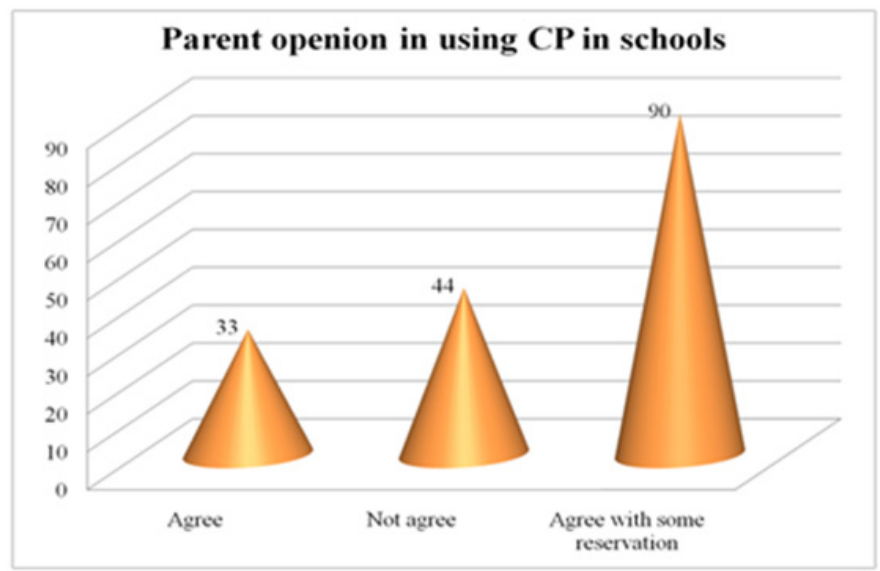

Figure I Parents opinion in using CP in schools.

\section{Existence of negative psychological and behavioral problems}

Only (88) of families responded to this question; among them $(42.0 \%)$ perceive their children as shy, $(28.4 \%)$ as stubborn or oppositional, $(18.2 \%)$ have fear problems, $(8.0 \%)$ as being violent and (3.4\%) of parents describe their children as having low self-esteem. No significant difference between the two schools as indicated by $\mathrm{p}$ value $(0.1)$. There was significant association between absence from school and school (A) as indicated by p value (0.03). (85.8\%) of parents from school (B) claimed that their children can easily share secrets with them, $p$ value $(0.021)$. No significant difference was found between schools (A) and (B) in secret sharing with teachers, which was $(73.3 \%)$, p value was $(0.59)$. (83\%) of parents claimed that their children were having more than (3) friends. There was significant association between school (B) and increase number of child's friends as indicated by $\mathrm{p}$ value $(0.053)$.

\section{Academic performance}

$(14.2 \%)$ of children who repeated the class were significantly related to school (A). $p$ value $<(0.001)$ (Figure 2$)$.

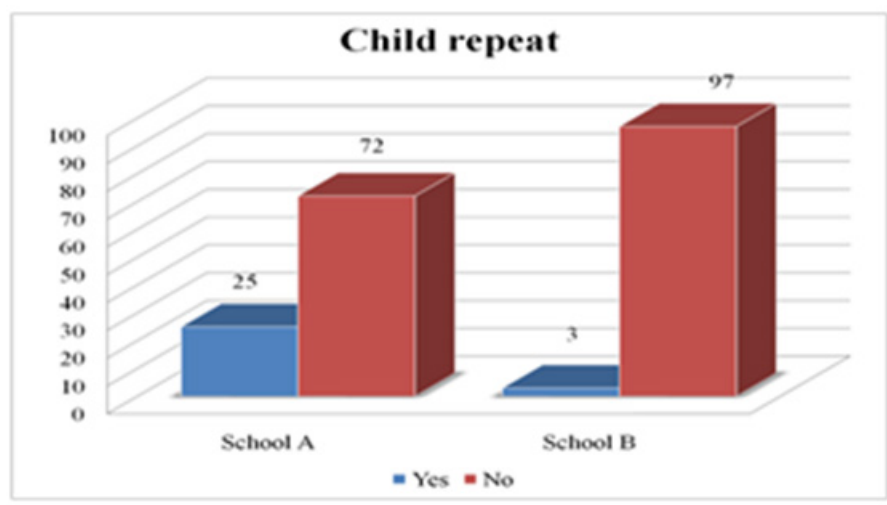

Figure 2 Children who repeated the class were significantly related to school.

\section{Parents thoughts about their children's Cha- racteristics}

Parents think that more than $(80 \%)$ of their children were regularly at school, committed on doing homework, has good relations with teachers, cooperative, popular, punctual, keen about school environment and actively participating in classes. parent think that less than $(5 \%)$ of their children were lying, stealing, often absent, not obedient, cruel, destroying things at school, or had weak performance at school. About $(2 \%)$ of parent didn't know anything about their children's characteristics. Positive characteristics (regular attendance at school, doing homework, clean, confident, honest, popular, and cooperative and participation during classes) found to have significant associations with school (B). Negative characteristics (low academic performance, fear, shy, stubborn, vandalism, disobedience, cruelty, continuous problems with teachers) found to have significant association with school (A).

\section{Bi- variable analysis}

Parents' age and education: Father and mother age and education were highly associated and positively correlated as indicated by $\left(\mathrm{X}^{2}=63.6043\right.$ and $\left.\mathrm{P}<0.001\right),\left(\mathrm{X}^{2}=227.51\right.$ and $\left.\mathrm{P}<0.001\right)$ respectively. Father and mother education were similarly highly associated with and positive correlation. That means we may expect increasing in the mother age and education when father age and education increased, and vice-versa. By using confirmatory factor analysis, both father and mother education variables can be merged into one variable that we can call it parent education. The same process applied on age variables as illustrated in structural (Figure 3).

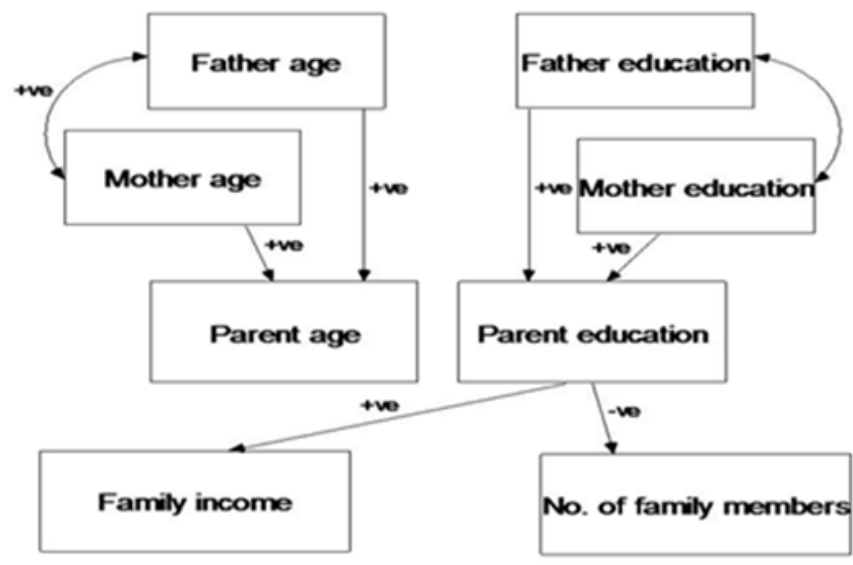

Figure 3 Structural representation for the relations between parents ages, education, number of family members and monthly family income.

Monthly family income and number of family members: Parent education is associated with number of family members with $\left(\mathrm{X}^{2}=37.98\right.$ and $\left.\mathrm{P}<0.001\right)$ and negative correlation. That means when parent education increases we expect the family member number to decrease. Parents education have a strong positive association with the family income (correlation=0.6). All previously relations shown in structural form Figure 3.

Observing parent quarrels and type of quarrel: Parent education (especially father) is associated and negatively correlated with children observing parent quarrels, $\left(\mathrm{X}^{2}=15.2231\right.$ and $\left.\mathrm{P}=0.02\right)$. In the same way, parent education is associated and negatively correlated with extreme form of parent quarrels (both verbal and physical violence $),\left(\mathrm{X}^{2}=21.5370\right.$ and $\left.\mathrm{P}<0.01\right)$.

Child motivation and rewarding: Parent education was positively associated with child motivation $\left(\mathrm{X}^{2}=54.1827\right.$ and $\left.\mathrm{P}<0.001\right)$. Correspondingly, family income and child rewording were positively associated $\left(\mathrm{X}^{2}=16.4178\right.$ and $\left.\mathrm{P}=0.051\right)$. The number of family members was found to be negatively associated to child rewarding, 
$\left(\mathrm{X}^{2}=12.7493\right.$ and $\left.\mathrm{P}=0.047\right)$.

Parental use of CP: Parent education (especially mother education) is associated with increasing of parental use of corporal punishment with $\left(\mathrm{X}^{2}=32.4196\right.$ and $\left.\mathrm{P}=0.02\right)$.

Parents believe about CP impact on child's behavioral and obedience: There was positive association between parental use of corporal punishment and their thoughts about $\mathrm{CP}$ ability to change the child behavior as indicated by $\left(\mathrm{X}^{2}=14.4109\right.$ and $\left.\mathrm{P}=0.025\right)$. Also the $\mathrm{CP}$ use was positively associated with parent believe in $\mathrm{CP}$ ability to improve the child obedience to orders $\left(\mathrm{X}^{2}=12.5865\right.$ and $\left.\mathrm{P}=0.05\right)$.

The child feelings toward the school: The use of CP at home was moderately and negatively associated to child who (likes his school) as indicated by $\left(\mathrm{X}^{2}=12.6512\right.$ and $\left.\mathrm{P}=0.049\right)$. (Child likes his school) was negatively associated with the absence from school as indicated by $\left(\mathrm{X}^{2}=21.1233\right.$ and $\left.\mathrm{P}<0.00\right)$. Absence from school was positively associated with the use of $\mathrm{CP}$ at school $\left(\mathrm{X}^{2}=6.5122, \mathrm{P}=0.039\right)$.

\section{Multivariable analysis}

Stepwise Logistic regression for the predictors of home corporal punishment shown that, the significant predictors of parental use of corporal punishment were: parent's education, monthly family income, parent's beliefs that $\mathrm{CP}$ improves the child behavior and the presence of severe form of parent quarrel (verbal and physical violence). The predictors of home (parent) use of corporal punishment can be summarized in structural Figure 4 .

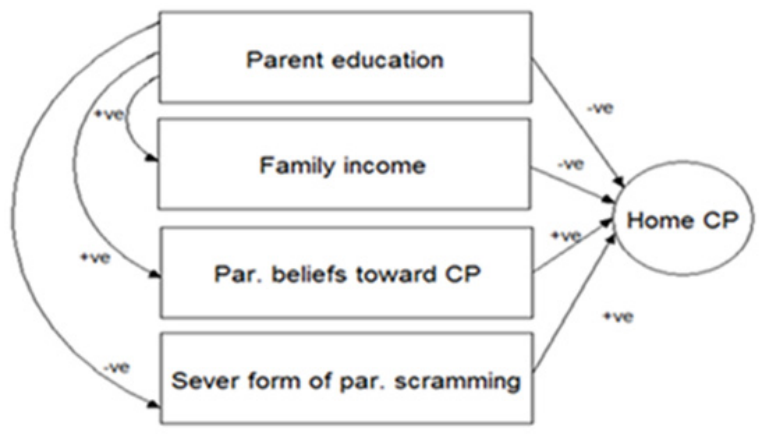

Figure 4 Structural representation for parent's use of corporal punishment after stepwise logistic regression.
Stepwise Logistic regression for the predictors of the child absence from school: The adjusted predictors for the child absent from the school as shown in the logistic regression are; child likes his school, home corporal punishment and school corporal punishment. These relations were illustrated in the structural Figure 5.

After comparing the Bi-variable and Multivariable outputs for the relation between the use of home and school corporal punishments; Home CP found to act as a moderator for the relation between school $\mathrm{CP}$ and the degree that the child likes his school. That means that the degree of the exposure to home CP modify the effect of school $\mathrm{CP}$ on the degree the child likes his school. Furthermore, the degree that the child likes his school acts as a mediator that explain the relationship between the $\mathrm{CP}$ from both home/school and the rate of absence from school. That means if this mediator removed the association between $\mathrm{CP}$ and child absence become of lower significance (Table 1).

Multiple linear regressions for the predictors of number of child friends: Both school and home $\mathrm{cp}$ were significant predictors for the child number of friends as shown from the stepwise linear regression model in Table 2. This relation had been merged with other many relations described the both home \& school CP as shown in structural Figure 6.

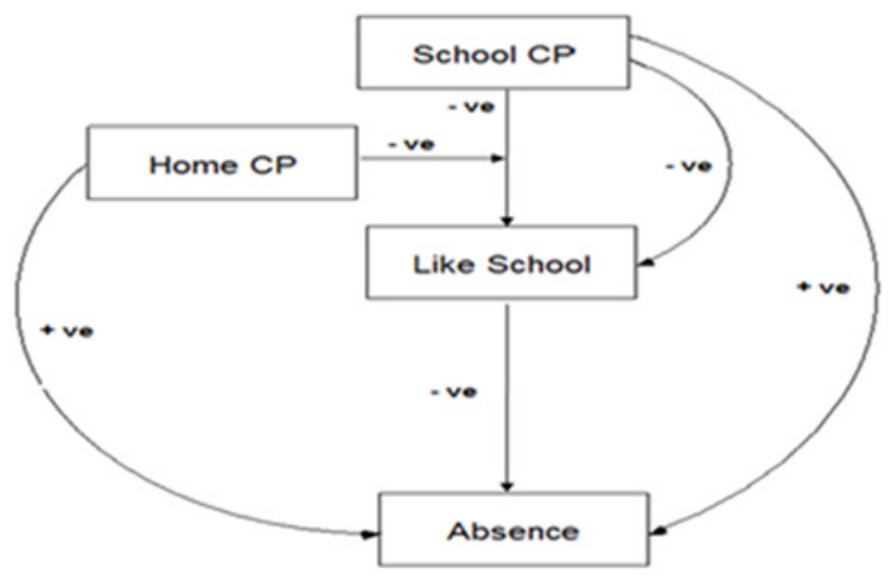

Figure 5 Structural representation for the predictor of child absence from the school after logistic regression.

Table I Child absence become of lower significance

\begin{tabular}{lllllll}
\hline $\begin{array}{l}\text { Dependent variable } \\
\text { (Absence from School) }\end{array}$ & Odds ratio & Std. Err. & $\mathbf{z}$ & $\mathbf{P > z}$ & \multicolumn{2}{c}{ [95\% Conf. Interval] } \\
\hline I Love School & 0.38 & 0.09 & 4.46 & 0.000 & 0.21 & 0.55 \\
2 Home CP & 1.9 & 0.808 & 2.30 & 0.022 & 0.27 & 3.44 \\
3 School CP & 6.4 & 5.186 & 2.18 & 0.028 & 1.3 & 31.2 \\
4 Observation of Parents Screaming & 0.52 & 0.29 & -1.19 & 0.24 & 0.18 & 1.52 \\
5 Parent Education & 0.59 & 0.4 & -0.79 & 0.43 & 0.16 & 2.19 \\
\hline
\end{tabular}

Table 2 Showing multiple linear regressions for the predictors of number of child.

\begin{tabular}{llllllc}
\hline Number of friends & Coefficient & Std. Err. & $\mathbf{t}$ & $\mathbf{P}>\mathbf{t}$ & \multicolumn{2}{c}{ [35\% Conf. Interval] } \\
\hline Home CP & 0.008 & 0.09128 & 0.08 & 0.935 & -0.173 & 0.188 \\
School CP & 0.028 & 0.08672 & 0.32 & 0.751 & -0.143 & 0.198 \\
Academic Effect & -0.148 & 0.09290 & -1.60 & 0.111 & -0.331 & 0.034 \\
Behavioral Effect & 0.206 & 0.07743 & 2.67 & 0.008 & 0.053 & 0.359 \\
Secrets Sharing & 0.0602 & 0.07588 & 0.79 & 0.428 & -0.089 & 0.209 \\
Intelligence & -0.016 & 0.07384 & -0.21 & 0.833 & -0.161 & 0.130 \\
_Cons & 0.960 & 0.12861 & 7.47 & 0.000 & 0.706 & 1.213 \\
\hline
\end{tabular}


Parental and school use of CP considered as a mediator for a number of friends that the child could have. The child number of friend could be explained through the use of both home/school CP according to the previous structure figure. Parental use of $\mathrm{cp}$ is the main negative contributor.

\section{Child characteristics}

As we found before that child's positive characteristics were significantly associated to school (B), not using CP, and child's negative characteristics were significantly associated to school (A) that using $\mathrm{CP}$. Home $\mathrm{CP}$ is acting as a mediator for the relation between school CP, the child characteristics and problems. In another words, since the correlations is more than 0.3 or less than -0.3 , we can consider the effect of school $\mathrm{CP}$ is significant on the various outcomes $\mathrm{BUT}$ varies according to the presence of home $\mathrm{CP}$.

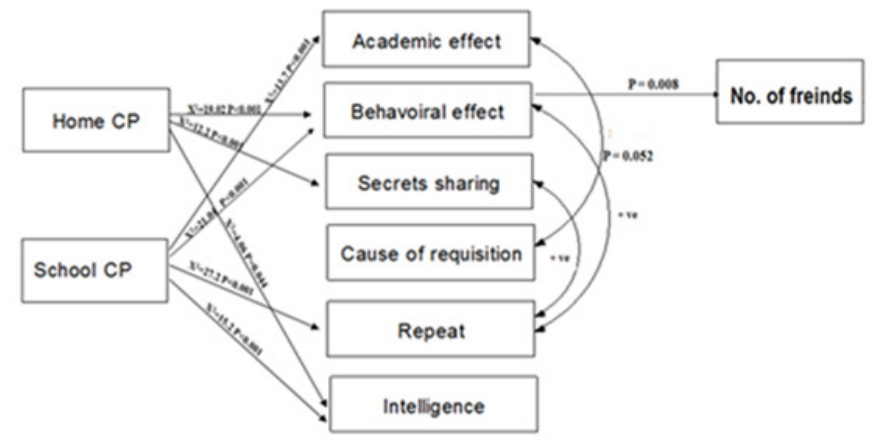

Figure 6 Structural representation for the effect of both home \& School CP

\section{Discussion}

\section{Parent socio demographic data}

In this sample there was no significant relation between parental age and use of CP. Parental age is an area of disparity in different studies for example; fewer younger parents use corporal punishment than those who are older as revealed by survey in South Africa. ${ }^{1}$ Parent young age found to be in other studies associated to use of CP. ${ }^{2}$ This result could be attributed to our socio cultural context, where CP is accepted tool of disciplining children. Using corporal punishment in Sudan for adults is part of public order laws and (Shariaa) Islamic laws.

The majority of families $71.5 \%$ are living with a monthly income of about 1000 SDG or less. Most of the families 54\% were living with 6-10members in the same house. Crowded houses and low family income were proved in literature as risk factors for physical abuse. ${ }^{3}$

\section{Child variables}

The majority of parents evaluate their child's intelligence as more than average $(64.6 \%)$. Significant relation between intelligence, home $\mathrm{CP}$ and school $\mathrm{CP}$ was found. The use of $\mathrm{CP}$ related to decrease intelligence. And if the $\mathrm{CP}$ affects the intelligence or the children low intelligence provoked $\mathrm{CP}$, this needs further investigation. Children with learning disabilities notably those with attention deficits or hyperactivities have high risk factors for physical abuse. ${ }^{3}$

\section{Use of CP and CP's variables and predictors}

The majority of parents were using $\mathrm{CP}$ to discipline their children at homes $83.4 \%$. This result was different than findings in other research where $90 \%$ of parents report that they sometimes spank their children below 5years and 30\% are using this with children from 5-12years- almost similar age group to this study. ${ }^{4}$ As children get older the parent change their disciplinary tools. The result findings could interpret by socio cultural believes in $\mathrm{CP}$ as a tool of discipline regardless the child age.

$47.0 \%$ of parents claimed that their children's school was using CP. The majority of parents $(73.7 \%)$ accepted the use of CP in schools; among them 53.9\% accepted with some reservations. Almost all the parents $(94.8 \%)$ were against ending CP in schools. There was significant difference between school (A) and (B) as indicated by $\mathrm{p}$ value (0.04). Where $(97.9 \%)$ of parents with school (B) were against ending CP. Parental believes about the ability of $\mathrm{CP}$ to change the child's behavior and ability to improve compliance to orders significantly increase the use of $\mathrm{CP}$ at school. This result showed the effect of parental pressure in school regulations and should be considered in preventive plans. Presence of $\mathrm{CP}$ at both home and school escalate the resulting problems as follows: Home CP act as a moderator for the relation between school $\mathrm{CP}$ and the degree that the child likes his school. Furthermore, the degree that the child likes his school acts as a mediator that explains the relationship between the $\mathrm{CP}$ from both home/school and the rate of absence from school. Where $4.7 \%$ of children were frequently absent from their schools they were mainly from school (A).

Parental and school use of CP considered as a mediator for a number of friends of the child. The main contribution was made by school CP. Similar finding was revealed by different studies where physical abuse leads to few if any friends. ${ }^{5}$ Bryan $\&$ freed found that college student who were physically punished in childhood manifest sever long-term effects including having fewer friends. ${ }^{6}$

Predictors of parental use of $\mathrm{CP}$ proved in this study as follows: Parental thoughts about the ability of CP to change the child's behavior and ability to improve compliance to orders increase the use of CP, P values (0.025), (0.05) respectively. This result was similar to other studies ${ }^{3}$ which found attitudes supportive of the use of physical punishment and non-empathic parenting attitudes are the most significant predictors of the severity of corporal punishment, and of these two factors, the first is the strongest predictor of severe corporal punishment. $^{\text {? }}$

Mother Low education was significantly associated to use of CP ( $p$ value 0.02 ). This result was similar to international studies that found a large number of cognitive- affective variables have been linked to physical abuse like parental inadequate knowledge. ${ }^{8}$ Parental low education in general found to be related to use of CP in other studies. ${ }^{3}$ Low income was similar to literature where poverty proved as risk factor for physical abuse. ${ }^{8}$ Domestic violence, especially with verbal and physical violence in front of children, result was similarly found in other studies, where participants who experience high levels of partner violence are also more likely to agree with physical discipline of children. ${ }^{7}$ Almost two thirds of parents $66.7 \%$ found that CP was helpful in immediate child compliance to orders. Most of the parents claimed that $\mathrm{CP}$ has little if any effect in disciplining their children while $49.7 \%$ of parents claimed that CP changed their children's behavior temporarily and $11.2 \%$ of parents thought that CP failed to change their children's behavior. This result was consistent with other studies that found the use of physical punishment may reduce children's moral internalization of the parental message. Long-term 
goals of Child-rearing, such as problem-solving, communication, attachment and trust, internalization, empathy and pro-social learning, are difficult to achieve when physical punishment is used. ${ }^{9}$ There was also indication that aggressive parents showed a distinct threegenerations trends for aggressive parents to have aggressive children. ${ }^{10}$ Gershoff ${ }^{11}$ wrote a report that synthesizes one hundredyears of social science research and many hundreds of published studies on physical punishment conducted by professionals in the fields of psychology, medicine, education, social work, and sociology, among other fields. The research supports several conclusions:

i. There is little research evidence that physical punishment improves children's behavior in the long term.

ii. There is substantial research evidence that physical punishment makes it more, not less, likely that children will be defiant and aggressive in the future.

iii. There is clear research evidence that physical punishment puts children at risk for negative outcomes, including increased mental health problems.

iv. There is consistent evidence that children who are physically punished are at greater risk of serious injury and physical abuse. ${ }^{11}$

School requisitions for behavioral problems, were confined only to school (A) such like (bullying (4.2\%), confrontations with teachers $(4.2 \%)$ and vandalism $(4.1 \%)$. Known outcome of CP is that it increases violent behavior by the punished childe as revealed by studies. ${ }^{12}$ Other studies showed that aggressive child was also aggressive adult. ${ }^{13}$ Another American study the relation between corporal punishment and future anti-social behaviors (ASB) of children revealed that: When parents use corporal punishment to reduce anti-social behavior, the long-term effect tends to be the opposite. The findings suggest that if parents replace corporal punishment by nonviolent modes of discipline, it could reduce the risk of (ASB) among children and reduce the level of violence in American society. ${ }^{14}$

Positive and desirable behaviors like sharing secrets with the parents, sociability and having more friends, regular attendance at school, doing homework, clean, confident, honest, popular, cooperative and participation during classes found to have significant associations with school (B). In another research about child sexual abuse done by the researcher; significant association between physical abusive mother and delayed disclosure was found. ${ }^{15}$ Negative undesirable behaviors like repeating the class, low academic performance, fear, shyness, stubbornness, vandalism, disobedience, cruelty, continuous problems with teachers, found to have significant association with school (A). This result was similar to international studies where the impact of corporal punishment on student's academic performance and personality development up to secondary level education. The study showed that; mild and severe punishment impedes the class participation, decreases the attendance and increases the dropout rate that is indicated by respondents likewise (39\%:61\%), 46\%:54\% and (24\%:76\%) respectively. There was strong association between corporal punishment and academic performance/ career. ${ }^{16}$ According to a new study involving two private schools in a West African-country, revealed that: Children in a school that uses corporal punishment performed significantly worse in tasks involving "executive functioning"-psychological processes such as planning, abstract thinking, and delaying gratification-than those in a school relying on milder disciplinary measures such as time-outs. ${ }^{17}$

\section{Limitations}

i. The research was limited to primary and governmental schools in Khartoum State. Geographical generalizations in rural areas and other cities cannot be possible.

ii. Private and primary schools for girls and higher secondary schools were not included.

iii. Some variables that test child's characteristics, feelings and psychological consequences were subjective and difficult to yield accurate measurable results and standardized scales were not used.

\section{Recommendations}

i. Increase community based research in the field of corporal punishment in homes, schools and different institutes.

ii. Raising awareness within the communities, with much concentration on the parent to challenge beliefs and attitudes.

iii. Teaching new methods of positive discipline and raising awareness of the negative effects of CP in homes and schools.

iv. Apply positive discipline in schools and assess with good research their impacts on children behavior and academic performances.

\section{Acknowledgements}

I would like to acknowledge and extend my heartfelt gratitude to the following persons who have made the completion of this research possible:

i. Ministry of education, training sector, Khartoum state and Child Rights Institute for this golden opportunity and help.

ii. Amna Osman, Ahmed Alawad Mohammed and Altyeb Mohammed Alamin Khalid for their hard work in data collection.

iii. School (A) and (B) primary schools for boys; teachers, PTAs, families and students for their generosity with time and their valuable efforts and support.

\section{Conflict of interest}

The author declares no conflict of interest.

\section{References}

1. Dawes A, Kafaar Z, de SasKropiwnicki ZO, et al. Partner violence, attitudes to child discipline \& the use of corporal punishment: A South African national survey. Child Youth \& Family Development, Human Sciences Research Council. Cape Town, South Africa; 2004. 8 p.

2. Hasinaburiah, Abdgamalsafa D, Amr D, et al. Abuse and Aljendr. daralvkr. Tabahalooly eman, Jorda; $2006.51 \mathrm{p}$

3. Hussein AR. msdr earlier. p. 51.

4. George WH. Parenting, a dynamic perspective. California, USA: SAGE publications; 2005. $191 \mathrm{p}$.

5. Hussein AR. msdr earlier. p. 57.

6. Heather AT, David F. Corporal punishment as a stressor among youth Journal of marriage and family. 1996;58:155-166.

7. Dawes A, Kafaar Z, de SasKropiwnicki ZO, et al. Pmt. 2004. 9 p.

8. George WH. Pmt. 290 p. 
9. Terry D. What do children tell us about physical punishment as a risk factor for child abuse? Social Policy Journal of New Zealand. 2007;30:160.

10. Schaffer HR. Child psychology. 8th ed. USA: Blackwell publishing; 2012. 333 p.

11. Gershoff ET. Report on Physical Punishment in the United States: What Research Tells Us About Its Effects on Children. Columbus, USA: Center for Effective Discipline; 2008. 57 p.

12. Heather A. Turner, David Finkelhor. Pmt. 156 p.

13. Huesmann LR, Eron LD, Lefkowitz MM. et al. Stability of aggression over time and generations. Developmental psychology. 1984;20(6):1120-1134.
14. Straus MA, Sugarman DB, Giles-Sims J. Spanking by Parents and Subsequent antisocial behavior of children. Arch Pediatr Adolesc Med. 1997;151(8):761-767.

15. Nahid MAA, Salah E, Haroun MD. Child Sexual Abuse in Khartoum-Sudan Pattern and Victim Associated Factors. Sudanese medical especialisation board, Sudan; 2012. $116 \mathrm{p}$.

16. Arab Naz, Waseem Khan, Umar Daraz. Pmt. 134 p.

17. www.sciencedaily.com/releases/2011/07/110726111109.htm 